\title{
Kentsel Bir Arayüz Olarak Kars'taki Rus Dönemi Kamu Yapıları Cephelerinin Göstergebilimsel Analizi
}

\section{Leyla Senem Görgülü ${ }^{1}$}

ORCID: 0000-0003-3564-2508

\author{
Cansu Hilal Polat ${ }^{3}$ \\ ORCID: 0000-0002-5530-1420
}

\author{
Ayşe Salman ${ }^{2}$ \\ ORCID: 0000-0003-0439-9293 \\ Arzu Özen Yavuz 4 \\ ORCID: 0000-0002-7197-289X
}

Öz

Sokakların, binalarm ve açı alanlarm oluşturduğu bozulmamış kentsel morfolojiler tarihi merkezlerin değerini belirlemektedir. Kentsel kimliği farkl toplumsal etmenlerin şekillendirdiği düşünüldü̈̆̈ünde 1878-1918 yıllarn arasinda özellikle Kars kent kurgusunda Ruslarm etkisi görülmektedir. Kentsel unsurlar arasinda ise kente kimliğini kazandiran temel unsur sokaklardır. Kentsel mekânnn dış yüzeyi olan kentsel arayüz, kamusal-özel alan arasındaki geçişi sağlamaktadır ve kent morfolojisinin okunmasına olanak vermektedir. Bu çalısmada, sokak ögesi üzerinden kentsel arayüzün düşey bileşeni olan cephelerdeki farkl kültürlerin tasarm dilinin çözümlemesi hedeflenmektedir. Kars'ta bulunan Haydar Aliyev Caddesinin barındırdığı çeşitli külttürel etkilerin ve farklı kullanım süreçlerinin saptanması amaçlanmaktadır. Çalı̧̧̧a yöntemi olarak cephenin göstergebilimsel parametreleri üzerinden analizi belirlenmiştir. Mimaride göstergebilimsel yöntemin kullanılması göstergelerin üretilmesini, yorumlamaları ve işaretlerin anlama süreçlerini beraberinde getirmektedir. Bu kapsamda çalışmanin yöntemini sokak ile iletişim arayüzü olan ve yapıldı̆̆ı dönemin veya kültürü̈n izlerini taşıyan cephelerin; kütle örgütlenmesi ve cephe özellikleri, cephe elemanlarmin simge ve bağlam özellikleri, cephe düzeninin yüzey ve derin seviyedeki göstergelerinin analizi oluşturmaktadır. Seçilen kamu yapılarının yansıttığı görsel mesaj ve yansittlan anlamlar irdelenmişstir.

Anahtar Kelimeler: Kentsel kimlik, göstergebilimsel analiz, Kars, kamu yapıları, Baltık mimarisi.

\footnotetext{
${ }^{1}$ Doktora Öğrencisi, Gazi Üniversitesi, E-mail: leylasenem.gorgulu@gazi.edu.tr

2 Yüksek Lisans Öğrencisi, Gazi Üniversitesi, E-mail: ayse.salman@gazi.edu.tr

${ }^{3}$ Yüksek Lisans Öğrencisi, Gazi Üniversitesi, E-mail: cansupolat57@gmail.com

${ }^{4}$ Doç. Dr., Gazi Üniversitesi, E-mail: arzuozen@gazi.edu.tr

idealkent @ Kent Araştırmaları Dergisi (Journal of Urban Studies)

http://idealkentdergisi.com

Geliş Tarihi Received Date: 09.07.2021 Kabul Tarihi Accepted Date: 14.12.2021
} 


\title{
Semiotic Analysis of Public Building Facades of Russian Period in Kars as an Urban Interface
}

\author{
Leyla Senem Görgülü ${ }^{5}$ \\ ORCID: 0000-0003-3564-2508
}

\author{
Cansu Hilal Polat ${ }^{7}$ \\ ORCID: 0000-0002-5530-1420
}

\author{
Ayşe Salman 6 \\ ORCID: 0000-0003-0439-9293 \\ Arzu Özen Yavuz ${ }^{8}$ \\ ORCID: 0000-0002-7197-289X
}

\begin{abstract}
The pristine urban morphology of streets, buildings and open spaces determines value of historical centers. Considering that different social factors shape urban identity, influence of Russians was seen especially in urban fiction of Kars between years 1878-1918. Among urban elements, main element that gives city its identity is streets. The urban interface, which is outer surface of urban space, provides transition between public-private spaces and allows morphology of city to be read. In this study, it is aimed to analyze design language of different cultures on facades, which are vertical components of urban interface, through street element. It is aimed to determine various cultural effects and different usage processes of Haydar Aliyev Street in Kars. The analysis of facade through semiotic parameters has been determined as a method. Using semiotic method in architecture brings along production of signs, interpretation, and understanding of signs. Accordingly, method of study is analysis of facades' indicators (mass organization-facade features, symbol-context features of facade elements, surface-deep level aspects of facade order), which are communication interface with street and carry traces of period or culture in which facade was built. The visual message reflected by selected buildings and reflected meanings were examined.
\end{abstract}

Keywords: Urban identity, semiotic analysis, Kars, public buildings, Baltic architecture.

\footnotetext{
${ }^{5} \mathrm{PhD}$. Student, Gazi University, E-mail: leylasenem.gorgulu@gazi.edu.tr

${ }^{6}$ MSc. Student, Gazi University, E-mail: ayse.salman@gazi.edu.tr

${ }^{7}$ MSc. Student, Gazi University, E-mail: cansupolat57@gmail.com

${ }^{8}$ Assoc. Prof., Gazi University, E-mail: arzuozen@gazi.edu.tr

idealkent @ Kent Araştırmaları Dergisi (Journal of Urban Studies)

http://idealkentdergisi.com

Geliş Tarihi Received Date: 09.07.2021 Kabul Tarihi Accepted Date: 14.12.2021
} 


\section{Giriş}

Tarih boyunca Selçuklu, Osmanlı gibi farklı medeniyetlere ev sahipliği yapmış olan Kars'ın bugünkü kent merkezi, 1878-1917 Rus döneminde Ruslar tarafından garnizon kenti olarak kurulan Kars vilayetinin bir mirasıdır. Birbiriyle dik kesişen gridal sistemde kentsel plan kurgusu caddelerde sıralı şekilde dizilmiştir (Ortaylı, 1978). Kars'ta sokakların genel dilini oluşturan Rus ve Baltık mimarisinin karışımı cepheler zaman içerisinde yeniden işlevlendirme altında değişikliğe uğramıştır. Rus yapıları özgünlüklerini kısmen yitirmiş olmalarına rağmen bölgeye hâkim olan Baltık mimari üslubunun genel olarak korunduğu ve cephelerde okunabildiği görülmektedir.

Çalışma kapsamında Kars İli Haydar Aliyev Caddesi üzerinde bulunan Rus-Baltık mimari üslubu ile inşa edilmiş günümüzde kamusal işlevde faaliyet gösteren yapılar belirlenmiştir. Kars ill Sağlık Müdürlügü Binası, Defterdarlık Misafirhanesi, Kars Ticaret ve Sanayi Odası Binası, Defterdarlık Binası ve Vali Konağı olarak kullanılan kamu yapıları göstergebilimsel yöntemle incelenmiştir. Sokak düzeninde seçilen binaların sokağın dilini oluşturmadaki etkisi belirlenmeye çalışılmıştır.

Kentsel mekânlar üretildikleri ve şekillendirildikleri toplumun tarihteki ve günümüzdeki özelliklerini, kültürünü, yaşam şekillerini, hedeflerini ve gereksinimlerini yansitmaktadır (Harvey, 2006, s.35-37). Tüm yapının anlamının ve gösterge sisteminin değerlendirilmesini cepheye dair farklı anlam katmanları şekillendirmektedir. Çalışmada seçilen yapıların kentsel kimliği bir arayüz olarak cephede yansıtmasının ortaya koyduğu anlamlar göstergebilim yöntem ile analiz edilerek kentsel kimliği belirleyen kültürel yap1nın etkisinin saptanması amaçlanmıştır. Lukken, Hirschfeld ve Searle (1993) tarafından geliştirilen binanın mimarisi için bir yorum bilimi olarak yararlanan göstergebilimsel yöntem kullanılmıştır. Bu çalışmada, cephelerinin göstergebilimsel analizi kütle örgütlenmesi ve cephe özellikleri, simge ve bağlam özellikleri, yüzey seviye ve derin seviye adımları ile incelenmektedir. Belirlenen Rus dönemi kamu yapılarının cepheleri analiz edilerek kentsel mekânın, üretildiği toplumun üretme pratiği ve kültüründen ne şekilde etkilendiği ortaya konulmuştur.

\section{Kentsel Kimlik}

Kimlik varlık gösteren herhangi bir şeyin biricik olma ve başka hiçbir şeye benzememe durumunu açıklamaktadır (Lynch, 1960, s.91). Tezcan (1999)'a göre bu bağlamda dünya üzerinde varlık gösteren her bir kent özgünleşme ve bireysel- 
leşme ile birlikte kentsel bir kimliğe sahip olmaktadır. Fakat kentsel kimliğin oluşumu uzun zaman gerektiren bir süreçtir. Bu süreç içerisinde kentin büründüğü kimliği oluşturmada içinde bulunduğu çevresel faktörler ve bu çevrede varlık göstermiş olan toplumların kültürleri ve yaşam biçimleri etkilidir.

Fiziksel anlamda vücut bulmuş olan kentlerde renk, doku ve biçime bağlı olarak bölgeye ait karakteristik çevre oluşmaktadır. Bulunduğu atmosfer içerisinde iklim, gece gündüz farkının yeryüzü üzerindeki renk ve doku etkisi, ışı-gölge ve yerleşmelerin durumu birleşerek kentin karakteri belirlenmektedir (NorbergSchulz, 1979, s.182). Toplumların sahip olduğu kültür ve yaşama biçimleri, kent geçmişi, bireylerin kentle aralarında kurduğu ilişki düzeyleri, bölgeye yükledikleri anlamlar, kent sanayisi, ticareti, turizmi, ekonomisi, yerel yönetimler ve alınan politik kararlar, toplumlara ait gelenek ve görenek kentsel kimliği oluşturan önemli etkenlerdir (Taşçığlu ve Atmaca, 2015).

Kentsel kimliğin şekillenmesinde bölgedeki mimarinin büyük etkisi bulunmaktadır. Barındırdığı toplumların ve içinde bulunduğu dönemin özelliklerini yansıtan kent mimarisi kullanı istekleri doğrultusunda tasarımciların elinde değişim ve gelişim göstermektedir. Kentin geçirdiği dönemlere ait mimari özellikler, kullanılan malzemeler, içinde barındırdığı toplumların sosyal ve ekonomik yapısl, yerel yönetimlerin istekleri ve tasarım ölçütleri mimarinin kentsel kimliğini yönlendirici faktörlerindendir (İgar, 2008, s.10).

Kentsel kimliği tanımlayı ögelerinin başında kamusal alanlar gelmektedir. Kamusal alanlar mekânsal ağların devamlılı̆ıı sağlamaktadır ve ortak kullanım alanı oluşturarak toplumsal bağların kuvvetlendirilmesine zemin hazırlamaktadır (Kürkçüoğlu, 2016). Kamusal alanlardan öznel alanlara geçiş mekânı ise Gehl, Brack ve Thornton (1977) tarafından arayüz olarak tanımlanmıştır. Arayüz, kentsel mekân ile yapılı çevre arasında ara bir yüzey olarak oluşur ve düzlemsel olmasının yanında hacimsel bir niteliğe de sahiptir (Özsel, 2009, s.27). Kentsel arayüzler öznel iç mekân ile kamusal dış mekân arasında bağlantı kuran, mekânın dışarı yansıtıldığı dış yüzeylerdir. Arayüzün yatay bileşenleri, yapının konumu, kütle ve kompozisyonu ile düşey bileşenleri ise mimari cephe dizini ve düşey kesitteki görünümlerle tanımlanır (Bala, 2006). Bu çalışma özelinde bina ile kent arasındaki bir arayüz olarak mimari cepheler seçilmiştir.

\section{Kars özelindeki kentsel kimlik}

Medeniyetler beşiği olarak adlandırılan Anadolu'nun sınır kentlerinden birisi olan Kars'ta insanlık tarih öncesi devirlere dayanmaktadır (Altunsoy, 2005, s.33). Kars çoğunlukla, günümüze kadar Türk-İslâm veya İslâm idarecileri tarafından yönetilmiş ve şehrin mimari geleneği de bu bağlamda ge- 
lişme göstermiştir. Kars'ın oluşması ve kentsel kimliğini edinebilmesi Kanuni Sultan Süleyman'ın 1548 yılında Kars'ta başlattığı imar çalışmalarıyla sağlanmıştır (Erişen, 2000, s.15). Başlatılan imar girişimleri günümüzde varlığını devam ettiren Kars'ın kentsel kimliğinde yer edinmiş eserlerle donatılmasını sağlamıştır (Arslan, 2020). Osmanlı Dönemi'nde şehirde yoğun olarak görülen dini yapılaşmanın yanı sıra saray, konut, hamam ve köprü gibi kent dokusunu biçimlendiren sivil mimari örnekleri de sıklıla görülmektedir (Gündoğdu, 2006, s.218-221).

19. yüzyılda Osmanlı hâkimiyetinde olan Kars ve çevresini Anadolu topraklarına önemli bir geçiş noktası olarak gören Ruslar 1828 ve 1855 tarihlerinde Kars'ı işgal etmiştir. Son olarak 1877-1878 yılları arasında yapılan Osmanlı-Rus Savaşı (93 Harbi) ile Rus ordusu 1877'de Kars'1 topraklarına katmıştır. Berlin Antlaşmasının (1878) yapılması ile beraber Kars, Batum ve Ardahan Rus İmparatorluğu hâkimiyeti altına girmiştir. Ruslar, Kars'ın merkezde olduğu Kars, Oltu, Ardahan ve Kağızman alt bölgelerinden oluşan idari birimi oluşturmuştur (Serbest ve Savaş, 2012). Kars'ın 1878-1918 yılları arasında süren 40 yıllık Rus dönemi başlamıştır (Gündüz, 2001, s.516). Bu dönem kent dokusunun farklı bir mimari anlayışa bürünmesine zemin hazırlamıştır (Gündoğdu, 2010). Kars'ın Osmanlı mahalleleri haricinde kazandığı bu yeni kimliğe yeni inşa edilen kiliseler, kamu binaları, konutlar ve ticari yapıların etkisi büyük olmuştur (Arslan, 2020).

Rus döneminde yapılan resmi, dini ve konut mimarisinde Hristiyan etkilerinin yanı sıra Kars'ın çok uluslu bir yapıya sahip olmasından dolayı Ermeni taş işçiliğinin izlerini görmek mümkündür (Karagöz, 2005, s.45). Azeriler, Kürtler, Terekemeler, Yerliler ve Türkmenlerin yer aldığı çeşitli etnik grupları bünyesinde bulunduran şehirlerden birisi olan Kars'ın (Özyakışır, 2017) kentsel kimliğinin oluşmasında çok kültürlü yapıya sahip olması büyük bir etkendir. Cumhuriyet Dönemi'ne gelindiğinde ise Kars ve çevresinde yeni imar faaliyetleri görülmeye başlanmıştır (Arslan, 2020).

\section{Osmanlı döneminde Kars'ta Rus Mimarisi}

Kars kent dokusunda Osmanl, Ermeni ve Rus dönemlerinden kente kazandırılmış yapılar bulunmaktadır. Şu anki kent merkezinin ve çalışma kapsamında seçilen Haydar Aliyev Caddesinin mimari dilini Rus yapıları oluşturmaktadır. Günümüze az sayıda yapısı ulaşan Osmanlı yerleşimi ise kale ve eteğinde dar ve organik sokaklar boyunca konumlanmaktadır (Arslan, 2015, s.7). Sıralı, çıkmalı ve sofalı geleneksel Türk sivil mimarisinde ahşap hatıllı taş duvar örgü cephe, düz dam ve boyutları, geleneksel Türk 
evi oranlarındaki kapı ve pencereler konut özelliklerini oluşturmaktadır (Türkan, 2017, s.22-23).

Rusların bölgeye hâkimiyetiyle Kars'ta Baltık stili olarak adlandırılan karma bir üslubun benimsendiği yeni mimari uygulamalar ortaya çıkmıştır. Baltık üslubu, Geç Avrupa stili Neoklasik üslup ile yerli Kafkas üsluplarının karışımı olan ve Baltık bölgesinde uygulanan bir üslup olarak tanımlanmaktadır (Gündoğdu, 2010). Bölgedeki karma üslup İskandinav ülkelerinin (Danimarka, Norveç ve İsveç gibi) çeşitli şehirlerinde görülmektedir (Akkurt ve Korkut, 2019, s.339). Kars'ta görülen üslup Orta Rusya (St. Petersburg, Kiev ve Moskova) mimari anlayışıyla benzer özellikler taşımaktadır (Şekil 1). Ayrıca, Rus yönetiminin Kars'ta kullandığı üslubun Avrupa'daki Neoklasik ya da eklektik mimarlık üslubundan farkı daha yalın ve mimari elemanların oranlarının farklı olmasıdır (Türkan ve Durak, 2016).

Rus yerleşimi kalenin güneyinde St. Petersburg'un kent plan sisteminde olduğu gibi gridal düzende birbirini dik kesen büyük caddelerle planlanmıştır. Çevresinde geç Baltık stilinde ve Rus üslubunda kilise, şapel ve katedraller olan açı meydanlar bulunmaktadır. Yerleşim en fazla 3 katlı, caddelerde bitişik nizamda sıralanan kat sistemleri, kornişler, saçaklar, çatı ve baca biçimleri, her katta farklılaşan sütun dizilimleri, dışa taşırılmış, rustika biçimi kesme taşları, üçgen alınlıklar ve andezit/bazalt taşı kullanılarak kurgulanmış cephelere sahip yapılardan oluşmaktadır (Gündoğdu, 2010).

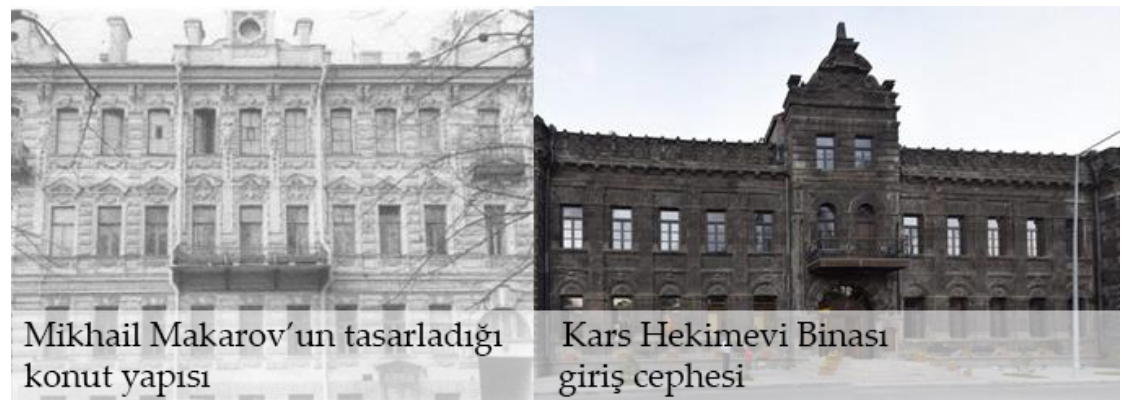

Şekil 1. Petersburg 1870 ve Kars Baltık mimari örnekleri (Kaynak: Brumfield, 1991, s.7;

Kars İl Kültür ve Turizm Müdürlüğü, 2021)

\section{Materyal ve Yöntem}

\section{Göstergebilimsel yaklaşım}

İnsanların ve toplumların varoluşunda iletişim önemli bir rol oynamaktadır. Görsellerle kurulan iletişim ise geçmişte ve günümüzde mesajı iletmedeki en temel ve etkili yol olarak yazılı iletişimden daha önce var olmuş- 
tur. $\mathrm{Bu}$ iletişim yapısı birtakım göstergelerden oluşan dizgelere sahiptir (Çağlar, 2012). Dilbilimsel anlama sahip bütün, gösterge olarak adlandırılmaktadır (Erman ve Ayalp, 2009). Bu göstergelerin anlamlarını, eklemlenmelerini inceleyen bilim dalı ise göstergebilim adını almaktadır (Denli, 1997, s.25). Göstergebilim, kültürü iletişim bakımından incelemektedir (Erkman, 1987, s.22). Ayrıca, anlam tabakalarının ortaya çıkmasında, sınıflandırma ve yorumlamalarda yardımcı olmaktadır (Erkarslan, 2009).

Mimarlıkta göstergeler bildiri özelliği barındırmaktadır (Güneş, 2013). Cephe elemanlarının tasarım kararları kentin kimliğini ve dilini şekillendirmektedir. Görsel iletişim sağlayan cephe, işlevsel özelliklere ve anlamsal değerlere sahip bir gösterge olarak tanımlanmaktadır (Şenyiğit ve Altan, 2011). Taşınan anlamsal değerler ise çeşitli yöntemlerle ortaya konulmaktadır. Anlamsal değerlerin iki düzeyde incelendiği Barthes'in (1976) kuramına göre anlamlamanın birinci düzeyi olan düz anlamda göstergenin neyi temsil ettiği, anlamlamanın ikinci düzeyi olan yan anlamda ise göstergenin nasıl temsil edildiği konusu ele alınmaktadır. Yananlam, mimaride amacı ve anlamı yansıtırken biçimden çok bireyin geçmişte neler yaşadığına ve geldiği kültüre bağlıdır (Ertürk, 1984, s.9-17; Şenyiğit, 2010, s.36).

Kentsel kimliğin devamlılı̆̆ında biçimsel ve anlamsal olguların bir arada olmasını sağlayan ilkeler etkilidir (Güler, Şahnagil ve Güler, 2016). Buna bağlı olarak kent yerleşkeleri barındırdığı anlamları koruyarak geçmiş ile olan bağını devam ettirmektedir (Hayta, 2016). Dolayısıyla, çağdaş ve geleneksel cepheler birbirini destekleyerek kentsel kimliği pekiştirmektedir. $\mathrm{Bu}$ kapsamda, toplumun kültürü, yapma biçimi bir dil olarak bina ve sokak ölçeğinde Kars kentini şekillendirmektedir. Kars kentini oluşturan mimari mekânların cepheleri içerdiği göstergebilimsel anlamlar ile kentin kimliğini oluşturmada önemli bir yere sahiptir.

\section{Göstergebilimsel yöntem}

Semiyotik analizler yapısal ve standart analizlerden farklılık göstermektedir. Araştırmacılar araştırma süreci bakımından daha bağımsız ve yaratıcı olarak nitelendirilmektedir. Temel olarak semiyotik araştırma süreci altı aşamadan oluşmaktadır (Echtner, 1999). Bu kapsamda çalışma metodolojisi adımları belirlenmiştir (Şekil 2). 


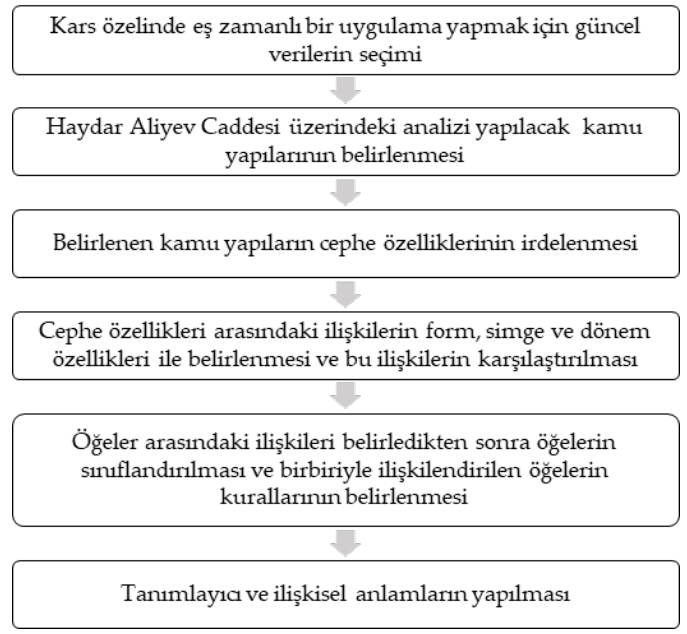

Şekil 2. Çalışma metodolojisi

Benimsenen analitik çerçevede Lukken vd. (1993) tarafindan geliştirilen göstergebilimsel yöntem temel alınmıştır. Bu yöntem, göstergebilimden binanın mimarisi için bir yorum bilimi olarak yararlanmaktadır. Tüm yapının anlamını ve gösterge sistemini daha iyi anlamak için cepheye dair farklı anlam katmanlarını analiz etmektedir (Guirguis, Dewidar, Kamel ve Iscandar, 2018). Çalışmada kullanılan cephenin göstergebilimsel incelenmesi adımları Şekil 3'de verilmiştir.

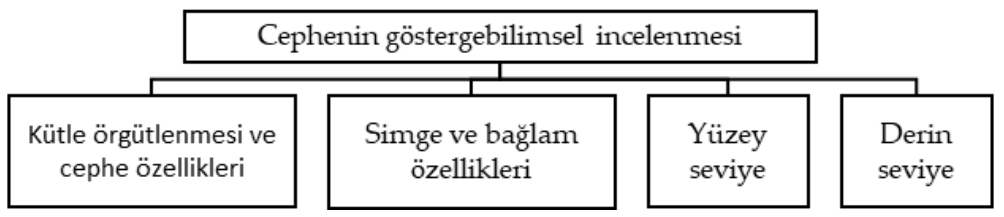

Şekil 3. Göstergebilimsel yöntem aşamaları

\section{Çalışma alanı}

Kars Çayı tarafinda başladığı yerde güneye doğru uzanan Haydar Aliyev Caddesi'nin Rus dönemindeki adı Gubernatorskaya Ulitsa'dır. Valilik caddesi anlamına gelen bu isim 1883 yılında inşa edilmiş olan Kars Askeri Valisinin Konağı'ndan kaynaklanmaktadır. Hem Haydar Aliyev Caddesi hem de paralelindeki Gazi Ahmet Muhtar Paşa Caddesi kent merkezinde Rus dönemine ait konut dışı yapıların sıklıkla görülebildiği caddelerdir (Rasimgil, 2017, s.37).

Kentin 1878-1918 yılları arasında Rus döneminde inşa edilen binaların ilk kullanım türleri hakkında bilgiler net değildir. Fakat Kars kent merkezinde kamusal binaların tasarımları ve plan örgütlenmeleri kamusal kullanıma yönelik olduklarını göstermektedir (Türkan, 2017, s.61). 
Çalışma kapsamında yapılacak analizlerin tutarlılı̆̆ı ve seçilen yapıların konumları açısından Kars Merkez'de bulunan Haydar Aliyev (Ordu) Caddesi üzerinde çalışılmasına karar verilmiştir (Şekil 4-6). Haydar Aliyev Caddesinin kimliğinin değeri, binalarının bir arada olmasına ve kullanımlarının devam etmesine dayanmaktadır. Tablo 1'de seçilen kamu yapılarının künyeleri gösterilmektedir.

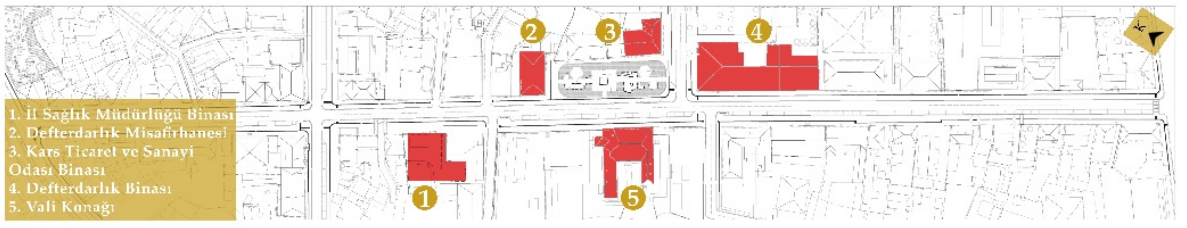

Şekil 4. Haydar Aliyev caddesi planı

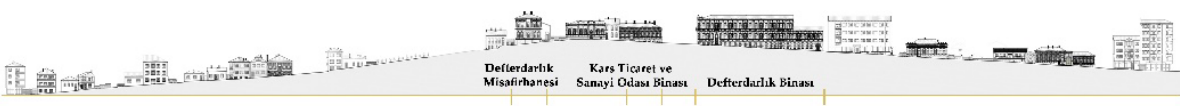

Şekil 5. Haydar Aliyev caddesi güneybatı silüeti

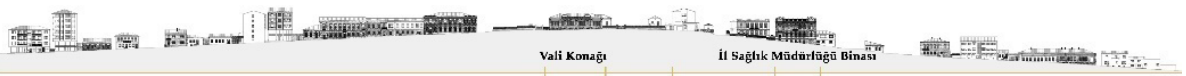

Şekil 6. Haydar Aliyev caddesi kuzeydoğu silüeti

Tablo 1. Bina künyeleri

\begin{tabular}{|c|c|c|c|c|}
\hline \multirow{2}{*}{ Bina ismi } & \multicolumn{2}{|l|}{ Tarihi } & \multicolumn{2}{|l|}{ Kullanım türü } \\
\hline & Yapım & Restorasyon & Rus dönemi & Sonraki dönem \\
\hline $\begin{array}{l}\text { İl Sağllk Mü- } \\
\text { dürlüğ̈̈ü Binası }\end{array}$ & 1907 & 1980 & Bilinmiyor & $\begin{array}{l}\text { 1923-1980: Kars } \text { Devlet } \\
\text { Hastanesi } \\
\text { 1980-günümüz: ìl Sağlık } \\
\text { Müdürlüğü }\end{array}$ \\
\hline $\begin{array}{l}\text { Defterdarlık } \\
\text { Misafirhanesi }\end{array}$ & 1897 & 1986 & Bilinmiyor & $\begin{array}{l}\text { 1923-1980: Adliye Binası } \\
\text { 1980-1986: Defterdarlık } \\
\text { Hizmet Binası } \\
\text { 1986-günümüz: Defterdar- } \\
\text { lık Misafirhanesi }\end{array}$ \\
\hline $\begin{array}{l}\text { Kars Ticaret ve } \\
\text { Sanayi Odası } \\
\text { Binası }\end{array}$ & $\begin{array}{l}\text { 19. yüzyıl } \\
\text { sonları }\end{array}$ & 2015 & Kışlık Konak & $\begin{array}{l}\text { 1923-günümüz: Kars } \\
\text { Ticaret ve Sanayi Odası } \\
\text { Binası }\end{array}$ \\
\hline $\begin{array}{l}\text { Defterdarlık } \\
\text { Binası }\end{array}$ & $\begin{array}{l}\text { 19. yüzyıl } \\
\text { sonları }\end{array}$ & 1983 & $\begin{array}{l}\text { Tiyatro } \\
\text { Yapısı }\end{array}$ & $\begin{array}{l}\text { 1923-1980: Hükümet Ko- } \\
\text { nağ1 } \\
\text { 1983-günümüz: Defterdar- } \\
\text { lık Binası }\end{array}$ \\
\hline Vali Konağı & 1883 & 2009 & Kışlık Konak & $\begin{array}{l}\text { 1923-günümüz: Vali Ko- } \\
\text { nağ1 }\end{array}$ \\
\hline
\end{tabular}

Kaynak: Türkan, 2017, s.69, 76, 90, 148, 153 


\section{Kars'taki Rus Dönemi Yapıların Göstergebilimsel Analizi}

\section{Kütle örgütlenmesi ve cephe özellikleri}

Geçmişten günümüze kadar olan süreçte insanların yapı inşa etmedeki temel amaçları çevresel unsurlardan korunması ve kişisel özelliklerine uygun bir atmosferin sağlanmasıdır (Olgyay, 2015, s.5). Günümüz yapıları şekillenerek çeşitli işlev ve formlara sahip mimari formlar oluşturmaktadır (Torabi ve Brahman, 2013). Kars kamu yapıları mimarisinin uzun vadeli gelişim sürecinde coğrafi konumu, doğal çevresi, iklim koşulları ve geçirdiği Rus dönemi etkilidir.

Binalarda topolojik özellikler bina girişi ve yönelimi parametreleri çerçevesinde değerlendirilmektedir (Şekil 9). Binalarda estetik özellikler kapsaminda renk kullanımı ve cephe tasarımı elemanları incelenmiştir. Tarihi binalar ve alanlar pitoresk niteliklere sahiptir. Modern sanayileşmiş yapı ürünleri ve inşaat sistemlerinin aksine zanaatkârlık ve bireysellik ön plana çıkmaktadır. Eski şehir yerleşimlerinde insan ölçeği, özen, zenginlik ve çeşitlilik bulunmaktadır (Appleyard, 1979, s.10-15).

Sanatsal modellemenin unsurlarından biri olan renk, göstergebilimde sembol olarak nitelendirilmektedir (Jing, 2018). Renk, antik ve modern mimari görüntülerin sergilenmesinde önemli bir rol oynayan görsel dil olarak tanımlanmaktadır. Bina cephelerinde renk kullanımı, bir bölgenin ve bir ulusun kültürel özelliklerini, mirasını ve sanat biçimini yansıtan temel ögelerin başında gelmektedir (Wang, 2021). Kars kamu yapıları renk tasarımı analizini yerel ögeler ve renk görsel dili oluşturmaktadır. Baltık kültürünün etkisindeki Kars kamu yapılarının renk estetiği ve mimari kökleri bakımından incelenmesi estetik parametreler kapsamında gereklidir (Tablo 2). Çalışmada Defterdarlık Misafirhanesi ile Kars Ticaret ve Sanayi Odası Binası ana giriş cepheleri, diğer kamu yapılarının ise Haydar Aliyev Caddesi'ne bakan cepheleri incelenmiştir. Yapılar giriş yol kotundan yükseltilmiştir. Giriş kapıları dikdörtgen formludur. Kamu yapılarının cephelerinin renkleri, kullanılan taş kaplamaya bağlı olarak değişmektedir. Pencerelerin üstünde farklı şekillerde kesme taş dizisinden oluşan lentolar bulunmaktadır. Çeşitli dekoratif kilit taşları ve söveler ön plana çıkmaktadır. Bina cephelerinde kat ve çatı silmeleriyle yatay algı vurgulanmak istenmiştir. Pencere altında ve üstünde yatay panolar kullanılırken dekoratif plasterler ile cephelerin düşey etkisi artırılmaktadır. 
Tablo 2. Cephe estetik özellikleri

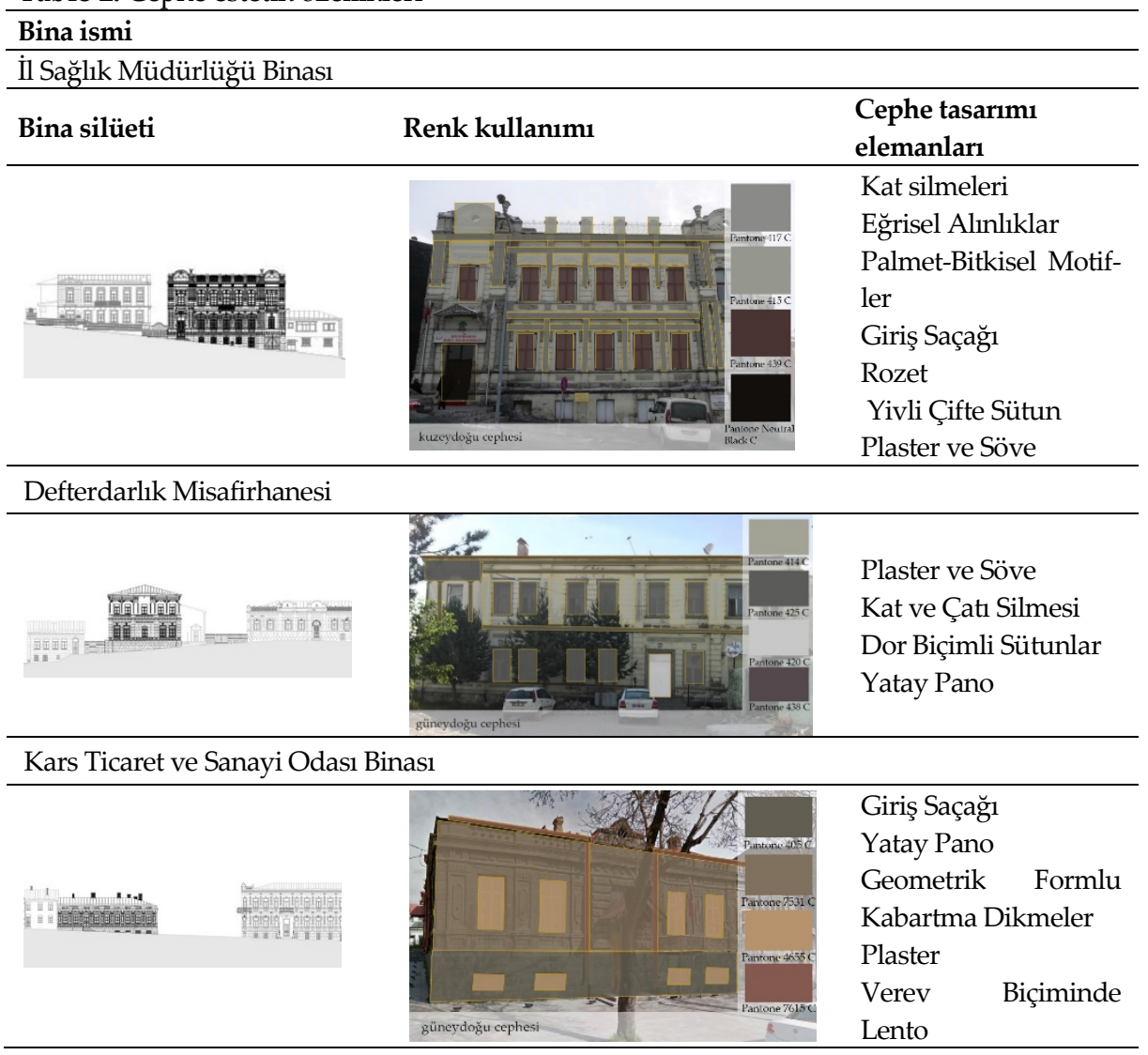

\begin{tabular}{lll}
\hline Defterdarlık Binası & \\
\hline Galiş Saçağ1 \\
Söve ve Plaster \\
Gömme Sütunlar \\
Çıma Balkon \\
Kabartma Taşı \\
Kemerli Giriş, Kilit \\
Taş1
\end{tabular}

Görsel ve çizimlerin alındığı ana kaynak: Türkan, 2017, s.71, 78, 94, 150, 156 (Analiz yazarlar tarafından yapılmıştır. 


\section{Simge ve bağlam özellikleri}

Etkinleştirme ve zamansallaştırma kapsamında bina cephesi üzerinde yapıldığı döneme ve özelliklerine dair bilgilerin olup olmamasına bakılmaktadır. Çalışmada seçilen binalar arasından yalnızca Defterdarlık Misafirhanesi'nin giriş kısmının üstünde 1897 yılı bulunmasına karşın kullanım amacı belirtilmemiştir. Bina cephelerinde işlevlerine dair yazılı bir metin bulunmamaktadır. Fakat cephe düzenlerinden kamu veya konak işlevi dâhilinde tasarlandıkları anlaşılmaktadır.

Mekânsallaştırma özelinde binalar incelendiğinde sokaktaki kamu bağlamı görülmektedir. Konu alanı olarak seçilen binalar çevrelerindeki diğer mekânlardan ayrılmaktadır. Binaların cephe düzenleri, vurgulanmış girişler ve dekoratif elemanlar ile mekânsal görünümleştirme güçlendirilmektedir (Şekil 7).
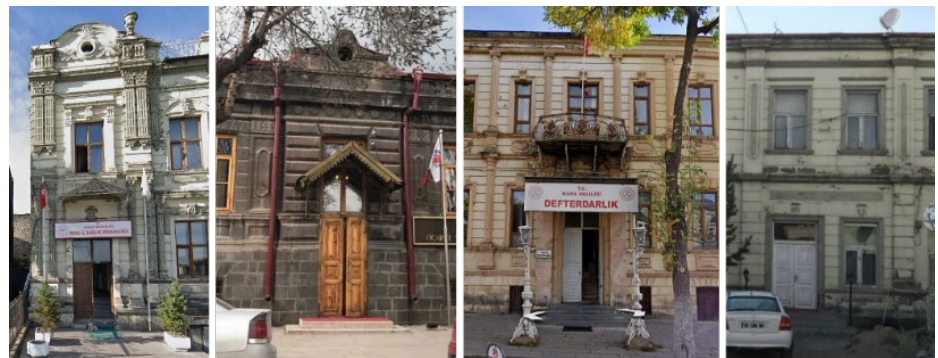

Şekil 7. İncelenen binaların girişleri (Kaynak: Google Earth, 2021; Türkan, 2017, s.71, 78)

Figüratifleştirme bakımından çalışmadaki binaların kitlesel yapısı önemlidir. Figürsel ögeler arasında genellikle bitkisel motifli korkuluk, kilit taşı, rozet, lento ve plaster gibi elemanlar bulunmaktadır (Şekil 8).
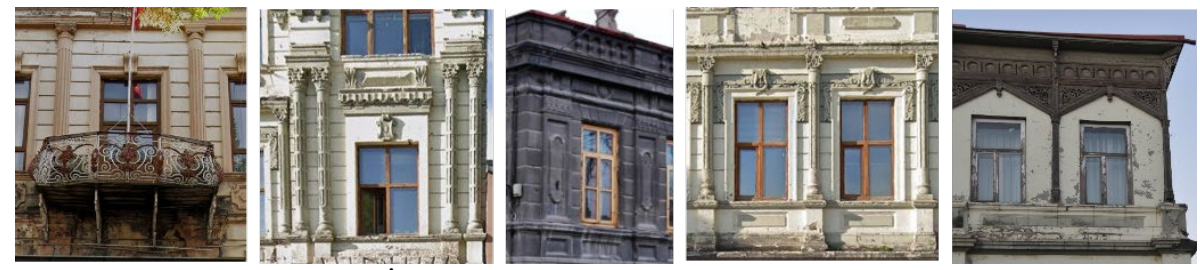

Şekil 8. İncelenen binaların figüratif öge detayları

(Kaynak: Google Earth, 2021; Türkan, 2017, s.94, 156)

Temalaştırma kapsamında incelenen kamu yapılarının giriş kapılarının konumu ve sayısı farklılık göstermekle beraber en nitelikli cephelerinin caddeye bakması organizasyonel kullanıma sahip olduklarını sergilemektedir (Şekil 9). 


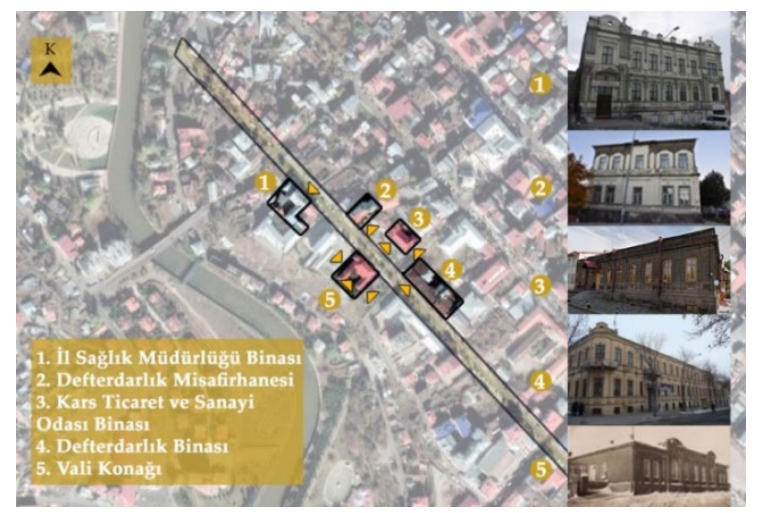

Şekil 9. İncelenen binaların girişleri, yönelimleri ve caddeye bakan cepheleri (Görseller:

Google Earth, 2021; Türkan, 2017, s.71, 78, 94, 150, 156)

\section{Yüzey seviye}

Yüzey seviyede insanların sokaktan kamu yapılarına geçişleri ile kullanıclların davranışlarının, bina cephesinin ve girişlerinin binayı şekillendirme biçimleri incelenmektedir. İncelenen yapılarda yükseltilmiş giriş, giriş saçağı, üçgen alınlıklar, yivli sütunlar ve pencere düzenindeki değişimler girişi vurgulayarak kullanıcıyı yapıya yönlendirmektedir. Tablo 3 yüzey seviyede bina ana girişlerinin özelliklerini göstermektedir.

\section{Derin seviye}

Derin seviye, bina cephesi tarafından yansitılan anlamları yöneten aksiyolojik değerlerle ilgilenmektedir (Lukken vd., 1993, s.13). Estetik ve etik ana bölümlerinden oluşan aksiyolojide estetik, güzelliği ve uyumu sağlayan ögelerin ne olduğunu ve nasıl sağlandığını araştırmaktadır (Dymchenko, Dakoro ve Dadiyan, 2021). Figüratif ve tematik yörüngelerin bazıları göstergebilimsel karede belirlenebilmektedir. Tablo 3'de derin seviyede bina cephelerinde estetiğin sağlanması için çeşitli figüratif elemanlar ve bu elemanların cephedeki örgütlenmelerine yer verilmiştir. İncelenen kamu binalarında tek veya üç bölüme ayrılan cephe düzeni kullanılmıştır.

Tablo 3. Yüzey seviye ve derin seviye bina cephe özellikleri

Bina ismi

ìl Sağlık Müdürlüğü Binası

Bina yönelimi $\quad$ Yüzey seviye

Derin Seviye 


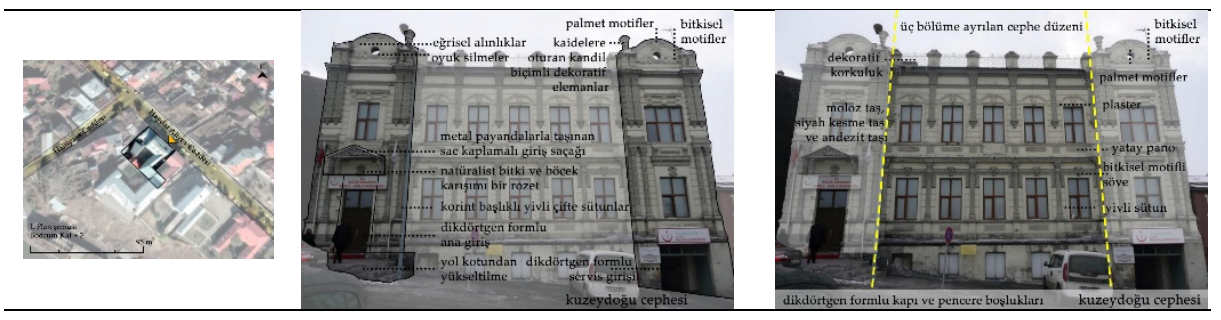

Defterdarlık Misafirhanesi
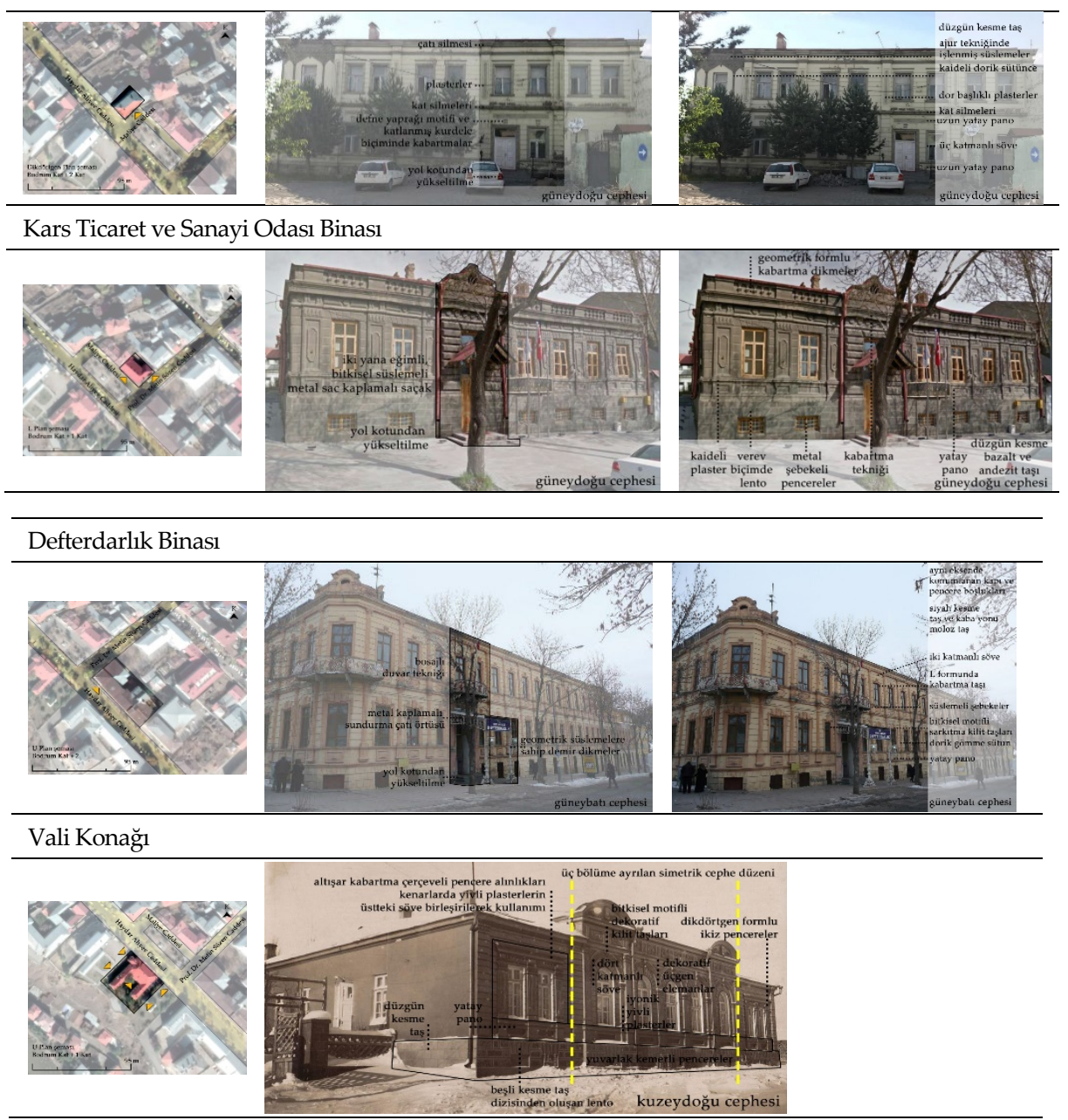

Görsel ve çizimlerin alındığı ana kaynak: Türkan, 2017, s. 71, 78, 94, 150, 156 (Analiz yazarlar tarafından yapılmıştır) 


\section{Değerlendirme}

Haydar Aliyev Caddesi'nden seçilen örneklerin uygulanan göstergebilimsel parametrelerle değerlendirilmesi Tablo 4'de verilmiştir.

Tablo 4. Örneklerin seçilen göstergebilimsel analiz parametreleriyle değerlendirilmesi

\begin{tabular}{|c|c|}
\hline Parametreler & Değerlendirme \\
\hline $\begin{array}{l}\text { Kütle örgütlenmesi } \\
\text { ve cephe özellikleri }\end{array}$ & $\begin{array}{l}\text { Kentsel kimliğe bir kültürün yansıması olarak Rus mimari- } \\
\text { sinin genel özellikleri incelenen kamu bina cephe düzenle- } \\
\text { rinde sergilenmektedir. Yapıların kütle örgütlenmeleri, } \\
\text { girişlerin konumları ve cephe özellikleri yapıların caddeyle } \\
\text { olan ilişkisine göre belirlenmiştir. }\end{array}$ \\
\hline $\begin{array}{l}\text { Simge ve bağlam } \\
\text { özellikleri }\end{array}$ & $\begin{array}{l}\text { Dönemin Rus mimarisinde yer bulan eklektik üslup incele- } \\
\text { nen örneklerin cephelerinde dekoratif elemanlar, bitkisel } \\
\text { motifli korkuluk, kilit taşı, rozet, lento ve plaster gibi figürsel } \\
\text { ögelerle yansitılmaktadır. }\end{array}$ \\
\hline Yüzey seviye & $\begin{array}{l}\text { Yüzey seviyede sokaktaki kullanıcıların davranışlarını yön- } \\
\text { lendiren ögeler cephede konumlandırılmıştır. Bu ögeler } 19 . \\
\text { ve 20. yüzyıllarda Avrupa'yı etkisi altına almış Rus mimari- } \\
\text { sinde de görülen eklektik üslubun yansımalarıdır. Bu özel- } \\
\text { likler sokak dokusunun dilini oluşturmaktadır. }\end{array}$ \\
\hline Derin seviye & $\begin{array}{l}\text { İncelenen örneklerde cephelerin belli bir düzen içerisinde } \\
\text { yatay ve dikey bölümlenmelerle oluşturulduğu görülmek- } \\
\text { tedir. Yatay bölümlenmeler kat ve çatı silmeleri ile sağlanır- } \\
\text { ken düşey bölümlenmeler gömme sütun, plasterler ve sü- } \\
\text { tuncelerle sağlanmıştır. Pencereler ve kapılar sövelerle çev- } \\
\text { relenmiştir ve aralarında yatay-düşey panolar kullanılmıştır. } \\
\text { Pencerelerin üst kısımlarında genellikle kilit taşları yer al- } \\
\text { maktadır. Girişlerde alınlıklar ve saçaklar girişi vurgulamak } \\
\text { için kullanılmıştır. }\end{array}$ \\
\hline
\end{tabular}

\section{Sonuç}

Kentler içinde barındırdığı toplumların etkisiyle kendi kentsel kimliğini oluşturmaktadır. Uzun bir süreç gerektiren bu oluşumda çevresel ve kültürel faktörler önemli bir rol oynamaktadır. Anadolu'daki kentler karma kültürlerin bileşimi ile oluşan özgün bir karaktere sahiptir. Kent yaşam kültüründeki bu çeşitliliğin ve zenginliğin yapılara yansımasının kent dokusunu zenginleştirdiğini görmek mümkündür. Farklı toplumların kentlere yerleşerek kendi tasarım dillerini taşıması Anadolu'da zengin dokular oluşmasında etkili olmuştur.

Tarihte çeşitli toplumlara ev sahipliği yapmış olan Kars kenti, günümüzde sahip olduğu kültür zenginliğini ve farklı tarih katmanlarını kentsel 
mekânlarında sergilemektedir. Kentsel mekânların kentliyle buluşmasını ve kamusal alanla ilişki kurmasını kentsel arayüz sağlamaktadır. Bu çalışmada, kentsel arayüzün düzlemsel düşey bileşeni olan cephelerden Kars'ın kültür katmanlarının analizinde yararlanılmıştır. Yapılan çalışma kapsamında Lukken, Hirschfeld ve Searle (1993) tarafından ortaya konulan göstergebilimsel yöntem kullanılarak çalışma alanı olarak belirlenen Haydar Aliyev Caddesi üzerindeki Rus dönemi kamu yapılarının cephe analizi yapılmıştır. Cephenin göstergebilimsel analizi kütle örgütlenmesi ve cephe özellikleri, simge ve bağlam özellikleri, yüzey seviye ve derin seviye adımlarından oluşmaktadır.

Analiz edilen kütle örgütlenmesi ve cephe özellikleri bölgedeki Baltık mimarisi kamu yapılarının çoğunlukla dikdörtgen formlu girişin yol kotundan yükseltildiğini, cephelerinin renklerinin kullanılan taş kaplamaya bağlı olarak değiştiğini, lentoların, dekoratif kilit taşlarının ve sövelerin ön plana çıktı̆̆ını göstermektedir. Simge ve bağlam özellikleri bakımından bina cephelerinde işlevlerine dair yazılı bir metin olmamasına karşın cephe düzenlerinden kamu veya konak işlevi dâhilinde tasarlandıkları anlaşılmaktadır. Ayrıca, binalar çevrelerindeki diğer mekânlardan cephe düzenleri, vurgulanmış girişler ve dekoratif elemanlar ile ayrılmaktadır. Yüzey seviyede girişi vurgulayıcı elemanlar ile kullanıc yapıya yönlendirilmiştir. Derin seviyede bina cephelerinde estetiğin sağlanması için çeşitli figüratif elemanlar ve örgütlenmeleri kullanılmıştır. Böylelikle bölgedeki Baltık mimarisinin kentsel bir arayüz olarak kent dokusuna kattı̆̆ değerler belirlenmiştir. Kars Kenti Haydar Aliyev Caddesi üzerindeki kamu yapıları, kentsel arayüz aracılığı ile kamusal alanlarda taşıdığı kentsel kimliği yansıtmaktadır. Bu çalışma, göstergebilimsel yöntemin mimaride uygulanması üzerine yapılacak araştırmalar için yol gösterici olacaktır. 


\section{Extended Abstract}

\section{Semiotic Analysis of Public Building Facades of Rus- sian Period in Kars as an Urban Interface}

\author{
Leyla Senem Görgülü \\ ORCID: 0000-0003-3564-2508
}

Cansu Hilal Polat

ORCID: 0000-0002-5530-1420

\author{
Ayşe Salman \\ ORCID: 0000-0003-0439-9293 \\ Arzu Özen Yavuz \\ ORCID: 0000-0002-7197-289X
}

Cities create their own urban identity with the influence of the societies they host. Environmental and cultural factors play an important role in this formation, which requires a long process. Cities in Anatolia have a unique character formed by the combination of mixed cultures. It is possible to see that the reflection of this diversity and richness in the urban life culture on the buildings enriches the urban texture. When different societies settled in the cities, they carried their own design languages and were influential in the formation of rich textures in Anatolia. The city of Kars, which has hosted various societies in history, exhibits its cultural richness and different layers of history in its urban spaces today. The urban interface provides the meeting of the urban spaces with the citizens and their relationship with the public space. In this study, facades, which are the planar vertical component of the urban interface, were used in the analysis of the cultural layers of Kars.

Within the scope of the study, the buildings that were built with the Russian-Baltic architectural style on Haydar Aliyev Street in Kars city center and currently used as public buildings were examined. Kars Provincial Directorate of Health Building, Revenue Office Guesthouse, Kars Chamber of Commerce and Industry Building, Revenue Office Building, and Governor's Mansion were the buildings analyzed with semiotic method. The semiotic method, which was developed by Lukken, Hirschfeld and Searle (1993), was used as a science of interpretation for the architecture of the building. In this 
study, the semiotic analysis of the facades is analyzed through mass organization and facade features, symbol and context features, surface level, and deep level steps. By analyzing the facades of the selected Russian buildings, it was revealed how the urban space was affected by the architectural practice and culture of the society in which it was produced.

Topological properties in buildings are evaluated within the framework of building entrance and orientation parameters. Entrances to the buildings except the Revenue Office Guesthouse and the Governor's Mansion are made through Haydar Aliyev Street. The examination of Kars public buildings under the influence of Baltic culture in terms of color aesthetics and architectural roots is necessary within the scope of aesthetic parameters (Table 2). In the study, public buildings', except the Revenue Office Guesthouse and Kars Chamber of Commerce and Industry Building, facades facing Haydar Aliyev Street were examined. All of the buildings' entrances have been raised from the road level. Entrances have rectangular shape doors. The colors of the facades of public buildings change depending on the stone coating used. Above the windows there are lintels made of cut stones in different shapes. Various decorative keystones and jambs stand out. Horizontal perception is aimed to be emphasized with floor and roof moldings on building facades. While horizontal panels are used under and above the windows, the vertical effect of the facades is increased with decorative plasters.

Within the scope of activation and temporalization, it is checked whether there is information on the facade of the building and its features. Among the buildings selected in the study, only the year 1897 is found on the entrance of the Revenue Office Guesthouse, but function of building is not specified. Although there is no written text on the building facades, it is understood from the facade layouts that they were designed with public or mansion function.

In terms of spatialization, when the buildings are examined, public context on the street is seen. The buildings chosen as the subject area are separated from the other spaces around them. Spatial appearance is strengthened by the facade layouts of the buildings, accentuated entrances and decorative elements. The massive structure of the buildings in the study is important in terms of figurativization. Among the figural elements, there are used such as floral-patterned balustrade, keystone, rosette, lintel and plaster in buildings. Although the location and number of the entrance doors of the public buildings examined within the scope of thematicization vary, the fact that the most qualified facades face the street shows that they have organizational use. 
The transition of people from street to public buildings and how the behavior of the users is shaped by the organization of the facade and entrances of the buildings are examined. The elevated entrance, entrance eaves, triangular pediments, fluted columns and changes in the window layout in the examined buildings emphasize the entrance and direct the user to the building. Table 3 shows the features of the building main entrances at the surface level.

The deep level is concerned with the axiological values that govern the meanings projected by the facade (Lukken et al., 1993, p.13). Axiology, which consists of the main parts of aesthetics and ethics, investigates what the elements that provide aesthetics, beauty and harmony are and how they are provided (Dymchenko, Dakoro and Dadian, 2021). Some of the figurative and thematic trajectories can be determined in the semiotic frame. In Table 3, various figurative elements and the organization of these elements on the facade are given in order to provide aesthetics on the building facades at deep level.

As a result of the study, the values that the Baltic architecture in the region added to the urban fabric as an urban interface were determined. The public buildings on Kars City Haydar Aliyev Street reflect the urban identity they carry in public spaces through the urban interface. This study will guide the researches on the application of the semiotic method in architecture.

\section{Kaynakça/References}

Akkurt, M. ve Korkut, T. (2019). Kars'taki Rus dönemi askeri garnizonlarda yer alan kilise örnekleri. G. Yılmaz, R. Çavuşoğlu ve M. Kulaz (Der.), Arkeoloji ve sanat tarihi araştırmalar: yapılar, buluntular, müzeler, çizim ve fotoğraflar eşliğinde içinde (s. 339-344). İstanbul: Hiper Yayın.

Altunsoy, A. (2005). Kentsel tarihi çevre koruma (Kars üzerine bir inceleme). Yayımlanmamış yüksek lisans tezi, Uludağ Üniversitesi, Bursa.

Appleyard, D. (1979). The conservation of European cities. Cambridge, Mass.: MIT Press.

Arslan, M. (2015). Kars demiryolu mirasinı koruma önerisi ve eski süt tozu fabrikası koruma projesi. Yayımlanmamış yüksek lisans tezi, İstanbul Teknik Üniversitesi, İstanbul.

Arslan, M. (2020). Kars'ın ahşap destekli köy camileri. Kafkas Üniversitesi Sosyal Bilimler Enstitüsü Dergisi, (26), 577-614.

Bala, H. A. (2006). Mimarlık-şehircilik, bina-kent, iç-dış, özel-kamusal arasında kentsel arayüzler. Yapı Dergisi, 293, 44-49.

Barthes, R. (1976). Göstergebilimin temelleri. Ankara: Kültür Bakanlığı.

Brumfield, W. C. (1991). The origins of Modernism in Russian Architecture. Berkeley: University of California Press.

Çağlar, B. (2012). Bir iletişim biçimi olarak göstergebilim. LAÜ Sosyal Bilimler Dergisi, $3(2), 22-34$. 
Denli, S. (1997). Göstergebilim açısından grafik gösterge anlamlarının incelenmesi. Yayımlanmamış yüksek lisans tezi, Atatürk Üniversitesi, Erzurum.

Dymchenko, M. E., Dakoro, M. F. ve Dadiyan, D. G. (2021). The problem of form in modern architecture. E3S Web of Conferences içinde (cilt 281, s. 02026). EDP Sciences, Rusya.

Echtner, C. M. (1999). The semiotic paradigm: Implications for tourism research. Tourism management, 20(1), 47-57.

Erişen, S. (2000). Serhat şehri Kars'ın tarihi ve turizmi. İstanbul: Şahsi Yayınları.

Erkarslan, Ö. (2009). Yeşil-yeşilimsi: Ürün göstergebilimi aracıllğıyla sürdürülebilir tasarım uygulamalarının eleştirisi. Mimarlık, 349, 75-79.

Erkman, F. (1987). Göstergebilime giriş. İstanbul: Alan Yayıncılık.

Erman, O. ve Ayalp, G. (2009). Cephe kaplama malzemelerinin simgesel anlamı, bir değerlendirme çalışması. İTÜ Dergisi Seri A: Mimarlık, Planlama, Tasarım, 8(1), 314.

Ertürk, S. (1984). Mimari mekânın algılanması üzerine deneysel bir çalışma. Doktora tezi, Yükseköğretim Kurulu Ulusal Tez Merkezi veri tabanından erişildi. (Tez numarası 378841).

Gehl, J., Brack, F. ve Thornton, S. (1977). The interface between public and private territories in residential areas. Department of Architecture and Building. Parkville: University of Melbourne.

Guirguis, M. N., Dewidar, K. M., Kamel, S. M. ve Iscandar, M. F. (2018). Semiotic analysis of contemporary Coptic Orthodox church architecture; A case study of Virgin Mary and Saint John the Baptist church in Bab El Louk, Cairo, Egypt. Ain Shams Engineering Journal, 9(4), 3093-3101. doi:10.1016/j.asej.2018.03.006

Güler, T., Şahnagil, S. ve Güler, H. (2016). Kent kimliğinin oluşturulmasında kültürel unsurların önemi: Balıkesir üzerine bir inceleme. Paradoks Ekonomi Sosyoloji ve Politika Dergisi, 11, 85-104.

Gündoğdu, H. (2006). Kars'ın anitsal yapıları. F. Özdem (Der.). Kars-beyaz uykusuz uzakta içinde (s. 195-227). İstanbul: Yapı Kredi Yayınları.

Gündoğdu, H. (2010). XIX. yüzyıl Kars yapılarına Baltık mimari üslubunun yansıması. Güzel Sanatlar Enstitüsü Dergisi, (18), 79-99.

Gündüz, T. (2001). Kars. Türkiye Diyanet Vakfı İslâm Ansiklopedisi içinde. (Cilt. 24, s. 515518). İstanbul: Türkiye Diyanet Vakfi Yayınları.

Güneş, A. (2013). Bir eserin mimarisini göstergebilimsel bir yaklaşımla okuma ya da mimari göstergebilim: Divriği Ulu Cami ve Darüşşifası. Erciyes İletişim Dergisi, 3(2), 74-86.

Harvey, D. (2006). Sosyal adalet ve şehir. (M. Moralı, Çev. 2. Baskı). İstanbul: Metis Yayıncllı. (Orijinal eserin yayın tarihi 1973).

Hayta, Y. (2016). Kent kültürü ve değişen kent kavramı. Bitlis Eren Üniversitesi Sosyal Bilimler Dergisi, 5(2), 165-184.

İgar, E. (2008). Kent kimliği ve kentsel değişimin kent kimliği boyutu: Eskişehir örneği. Yayımlanmamış yüksek lisans tezi, Anadolu Üniversitesi, Eskişehir. 
Jing, Z. (2018). The expression and application of the characteristics of color symbols in advertising design. X. Song (Der.), The International Conference on Educational Research, Economics, Management and Social Sciences (EREMS 2018) içinde (s. 6265). Francis Academic Press, Birleşik Krallık. doi:10.25236/erems.2018.014

Karagöz, E. (2005). Kars ve çevresinde aydinlanma hareketleri ve sol geleneğin tarihsel kökenleri 1878-1921. İstanbul: Asya Şafak Yayınları.

Kars İl Kültür ve Turizm Müdürlüğü (2021). Kars Hekimevi Binası. 20 Haziran 2021 tarihinde https://kars.ktb.gov.tr/TR-54889/xixyy-baltik-mimari-ornekleri.html adresinden erişildi.

Kürkçüoğlu, E. (2016). Etkileşim arayüzü olarak meydanlar ve yönetimi. Meydanlarda Tasarım, Yönetim ve Organizasyon Sempozyumu içinde (s.165-176). İstanbul.

Lynch, K. (1960). The image of the city. Cambridge: The Technology Press\&Harvard University Press.

Lukken, G., Hirschfeld, Y. ve Searle, M. (1993). Semiotics and church architecture: applying the semiotics of AJ Greimas and the Paris School to the analysis of church buildings. Kampen: Kok Pharos Publishing House.

Norberg-Schulz, C. (1979). Genius loci: Towards a phenomology of architecture. New York: Rizzoli International Publications.

Olgyay, V. (2015). Design with climate: bioclimatic approach to architectural regionalism-new and expanded edition. New Jersey: Princeton University Press.

Ortaylı, İ. (1978). Çarlık Rusya'sı yönetiminde Kars, Tarih Enstitüsü Dergisi, 9, 343-362.

Özsel, S. B. (2009). Bina-Kentsel mekân arayüz özelliklerinin kentsel yaya mekânlarına etkisi. Yayımlanmamış yüksek lisans tezi, İstanbul Teknik Üniversitesi, İstanbul.

Özyakışır, D. (2017). Göç olgusuna etnik kimlik açısından bir yaklaşım: Kars örneği, Uluslararası Sosyal Araştırmalar Dergisi, 10(52), 1130-1138.

Rasimgil, M. (2017). Rus yönetiminde Kars şehir merkezinin imar ve antsal yapılar. Yayımlanmamış yüksek lisans tezi, İstanbul Teknik Üniversitesi, İstanbul.

Serbest, B. D. ve Savaş, N. (2012). Kars ve çevresinde Rus yönetimi (Karskaya Oblast 1878-1917). 38. Uluslararası Asya ve Kuzey Afrika Çalışmaları Kongresi (ICANAS 2012) içinde (s. 2715-2734). Ankara.

Şenyiğit, Ö. (2010). Biçimsel ve anlamsal ifade aracı olan cephelerin değerlendirilmesine yönelik bir yaklaşım: İstanbul'da Meşrutiyet ve Halaskargazi Caddeleri'ndeki cephelerin incelenmesi. Yayımlanmamış doktora tezi, Yıldız Teknik Üniversitesi, İstanbul.

Şenyiğit, Ö. ve Altan, İ. (2011). Anlamsal ifade arac olan cephelerin değerlendirilmesine yönelik bir yaklaşım: İstanbul'da Meşrutiyet Caddesi'ndeki cephelerin incelenmesi. Megaron, 6(3), 139-150.

Taşçıŏlu, S. ve Atmaca, M. (2015). Tarihi kentlerde kimlik kavramı: Kilis örneği. Mustafa Kemal Üniversitesi Ziraat Fakültesi Dergisi, 20(1), 54-63.

Tezcan, E. Ö. (1999). Özgün çevrelerde tarihi ve kültürel mirasın sürdürülebilirliği ve yeni binaların, kent kimliği ve kentsel süreklilik üzerindeki etkileri. Yayımlanmamış yüksek lisans tezi, İstanbul Teknik Üniversitesi, İstanbul. 
Torabi, Z. ve Brahman, S. (2013). Effective factors in shaping the identity of architecture. Middle-East Journal of Scientific Research, 15(1), 106-113.

Türkan, S. (2017). Kars'ta Rus Dönemi'nde (1878-1918) inşa edilen yapıların cephe özelliklerinin analizi. Yayımlanmamıs yüksek lisans tezi, Uludağ Üniversitesi, Bursa.

Türkan, S. ve Durak, S. (2016). Kars'taki Rus dönemi (1878-1918) yapılarının çatı ve cephe özellikleri. 8. Ulusal Çatı E Cephe Sempozyumu. İstanbul.

Wang, X. (2021). Color analysis and application in art design of exterior environment of buildings. Y. Zhang, T. Volodina ve X. Zang (Der.), The 6th International Conference on Arts, Design and Contemporary Education (ICADCE 2020) içinde (s. 440-444). Atlantis Press. doi:10.2991/assehr.k.210106.086 